\title{
Issue Analysis of Competency-Based Mathematics Curriculum Design in African Countries: A Case Study of Mozambique's Primary Mathematics Education
}

\author{
Satoshi Kusaka ${ }^{1}$ \\ ${ }^{1}$ Graduate school of International Development and Cooperation, Hiroshima University, Hiroshima, Japan \\ Correspondence: Satoshi Kusaka, 1-5-1 Kagamiyama, Higashi-Hiroshima City, Hiroshima, 739-8529, Japan. \\ E-mail: Kusaka@ksm.world
}

Received: November 18, 2019

Accepted: December 15, 2019 Online Published: December 31, 2019

doi:10.5539/jel.v9n1p41

URL: https://doi.org/10.5539/jel.v9n1p41

\begin{abstract}
The paper firstly clarified the characteristic of competencies being discussed in African countries by comparing them with competencies being discussed in developed countries. It has become clear that both countries are very similar. In other words, against the background of rapidly increasing internationalization and globalization, the competencies required to live in the society of the future are the same across borders, regardless of whether in a developed country or a developing country. Secondly, using Mozambique as a case study, how the competencies are actualized and what kind of challenges they face are discussed by analyzing primary mathematics curriculum, textbooks and in classes. An emphasis was placed on the ability to use social, cultural and technological tools used in an interactive manner in the competencies that were contained in the 2015 curriculum. However, most of the contents of the new textbook focus on "basic competencies" centered on basic knowledge and skills. Furthermore, there were many classes where teachers presented questions listed in the textbook as they are. Hence, it became apparent that the nurturing of practical competencies listed in the curriculum was largely reliant on the abilities of the teacher.
\end{abstract}

Keywords: mathematics curriculum, competency-based curriculum, competency, teaching and learning

\section{Introduction}

Due to the advancement of globalization in the 21 st century and the emergence of a knowledge-based society in which knowledge in various fields is viewed importantly, the term "competency" has attracted attention. In particular, it has come to be discussed throughout the world since it was advocated in the Organization for Economic Cooperation and Development's (OECD) definition and selection of competencies (DeSeCo) project (Rychen \& Salganic, 2003). In a society organized along the lines described above, one is not only required to gain knowledge defined by "what one knows" but also to develop skills of "what one can do" with the knowledge; hence, one is demanded to apply knowledge and skills in real life and society to solve real problems. The idea of each individual learning in an idiosyncratic manner, acquiring information, synchronizing knowledge, and spawning new ideas and knowledge (that is, differences) in an educational system has started to be an integrated goal (Collins \& Halverson, 2009). To this end, the OECD DeSeCo project has merged these key competencies together and has had a major impact on the discussion of educational reform around the globe. According to the National Institute for Educational Policy Research (2013), places such as the EU, England and the USA define skills required in 21st century based on these key competencies, promoting curriculum development.

This type rhetoric is not limited to developed countries, but also applies to developing ones. In recent years, the United Nations, Educational, Scientific, and Cultural Organization (UNESCO) and the International Bureau of Education (IBE) have held workshops related to competency-based curriculum development in all African countries, and many of these nations administer competency-based curricula (UNESCO \& IBE, 2013, 2015). Furthermore, L'Organisation Internationale de la Francophonie (OIF) has provided financial assistance to 23 Francophone African nations and other types of support related to competency-based curriculum development (Bernard, Nkengne, \& Robert, 2007; Roegiers, 2008). In addition, the East African Community Common Curriculum Framework (2013 Harmonized Curriculum Framework for the East African Community) proposed 
by East African Community in 2013 as a reginal framework in Africa have stressed the importance of competency-based curricula and suggested key competencies common to the East African community in primary education: And in nations aligned to the East African Community, introduction of these curricula have been actively discussed and promoted.

In keeping with this, revisions to competency-based curricula have been advanced in African countries since the start of the 2000's, and in recent years this trend has only gotten stronger. Despite this trend, specific research concerning the actual nature of these revisions and whether they are being carried out appropriately is in short supply.

\section{Objectives}

In this study, firstly, the characteristics of competencies being discussed in African countries are clarified by comparing them with competencies being discussed in developed countries. Secondly, using Mozambique as a case study, how the competencies are actualized and what kind of challenges they face are discussed by analyzing primary mathematics curriculum, textbooks and in classes.

\section{Research Questions}

Two research questions were established to achieve the objectives indicated above:

1) What is the difference between competencies being discussed in African countries and competencies being discussed in developed countries in policy level?

2) What are the current status and related issues in Mozambique concerning competency-based mathematics educational design in curricum, textbooks and thier implementation?

\section{Method}

The following research methods were adopted in order to clarify the research questions described in previous section, as well as to achieve the objectives set forth in this study.

1) We compare and analyze the characteristics of the discussions concerning competencies discussed in both developed and African countries. We use the common curriculum framework of the East African Community when addressing African nations.

2) We then analyze three types of pedagogical items: curricula, textbooks, and lessons in terms of the current state of and issues concerning Mozambican competency-based mathematics education design.

More specific methods are described in the following:

- We compare and analyze descriptions concerning competencies in the primary mathematics curriculum that took effect in 2004 and 2015

- We analyze and investigate government-designed textbooks that were created based on the 2015 curriculum from the viewpoint of competencies described in the curriculum

- We observe two public primary school mathematics classes in capital city Maputo, Mozambique, and analyze and investigate them from the perspective of competency acquisition as described in the curriculum.

3) Based on the results obtained in sections 1 and 2, we consider issues related to competency-based mathematics education design focusing on the connection among the curricum, textbooks and their implementatios.

\section{Limitation}

In this study, we used a case study in addition to theory and document analysis in order to achieve the research objective of exploring the current status and challenges of competency-based mathematics educational design. However, since the number of observed lessons is two, it is possible to grasp the characteristics of the lessons for the analysis but not enough to generalize those considerations.

\section{Result and Discussion}

\subsection{Key Competencies Advocated by OECD}

Key competencies advocated by the OECD "Definition and Selection of Competencies (DeSeCo)" project are "within a set of tangible conditions, utilizing a given context (knowledge and skills), carefully thinking when acting and the ability to respond to complex needs and topics". As shown in the following diagram, there are three categories that make these competencies up: "the ability to use tools interactively", "the ability to interact in heterogeneous groups" and "the ability to act autonomously". These three key competencies are arranged 
similarly to three-dimensional coordinates and they maintainins interrelationships with other key competencies. As it could be said that these three interrelated key competencies were required for individuals to achieve their more complex goals, and as such demanded more than mastering a narrowly defined skill (Rychen \& Salganik, 2003); these three key competencies are correlated with one another, and how acquired knowledge and skills can be implemented in the real world is considered and became the focus of the curriculum design. In addition, as described as the ability to interactively use social, cultural, and technological tools, it could be claimed that these abilities do not go just one way but use communication with other parties. Part of this "key competencies" concept is also used in the framework of the Programme for International Students Assessment (PISA), and can be seen within the fields of reading, mathematical and scientific literacies.

The OECD also presented three new categories of competencies in the Education 2030 project: "Creating new value", "Reconciling tensions and dilemmas", and "Taking responsibility" (Howells, 2018). We transplanted these competencies into the context of mathematics education and considered why such competencies were established. In a world of increasing uncertainty, under complex situations where interests conflict in everyday life and the arenas of local and international communities, judgments based on emotionally informed preferences or transitory thinking may be made. In order to avoid this, it is necessary to have an accurate grasp of the problems one may be facing. Therefore, it is necessary to acquire reliable mathematical knowledge and skills, and to use them to attain the ability to acquire an astute temperament that is based on social values such as equality, fairness, and sustainability. Additionally, in order to cultivate the democratic ability of solving problems by the recognition of diverse values and discussion, the ability to use mathematics for problem solving and to use this skill to make social judgments is deemed as vital. This also applies to conveying and validating these mathematical skills and their associated judgments to those possessing different value sets. Thus, these newly established competencies would also be very important in the context of mathematics education.

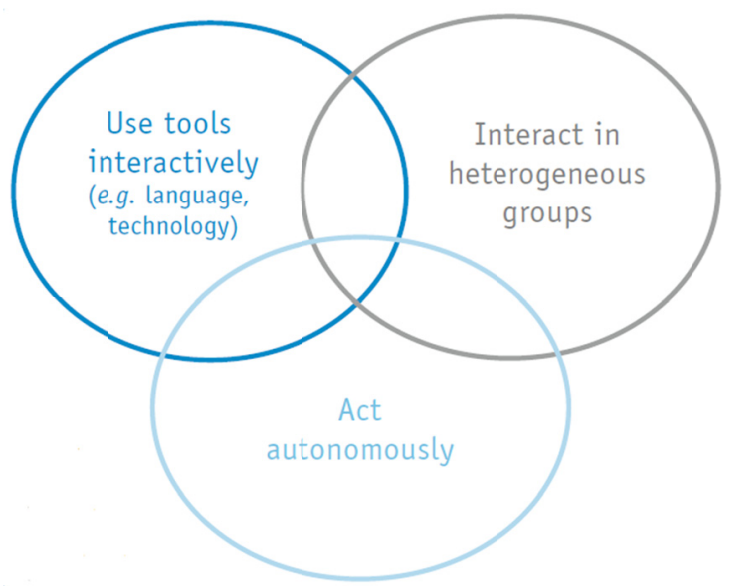

Figure 1. Structure of key competencies advocated by OECD

Source: OECD, 2003, 5.

\subsection{The Four Dimensions Proposed by the Center for Curriculum Redesign (CCR)}

Fadel, Bialik and Trilling (2015) have indicated, as 21st century-oriented skills and competencies featuring various commonalities within a global framework, they can be grasped being subdivided and arranged by the following four dimensions; knowledge, skills, character qualities, meta-learning strategy proposed by CCR. What is the characteristic in the framework shown by CCR is that meta-learning is lined up as the fourth dimension. As stated, the significance of this dimension; "It is not enough to implicitly include this fourth dimension in all the other dimensions - its significance must be highlighted explicitly (p. 41)", meta-learning is treated as an independent dimension. This concept aligns closely with the skills referred to as "learning to learn" contained in the EU's "Key Competencies for Lifelong Learning" (European Commission, 2007) and ATC21S (Griffin, McGaw, \& Care, 2012) "21st Century Skills". It is doubtless that meta-learning (learning to learn) is an indispensable quality/capability in a modern society that is marked by fluctuations and uncertainty, where lifelong learning is sought. 


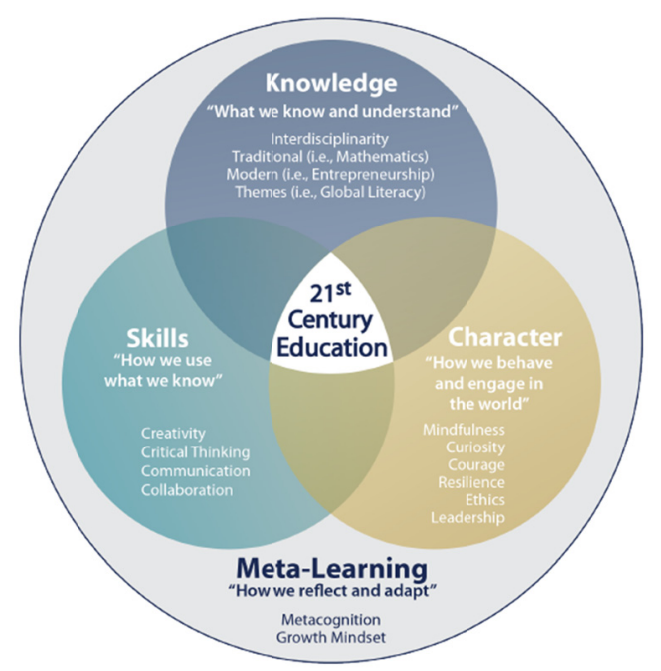

Figure 2. The four dimensions proposed by CCR

Source: Fadel, Bialik and Trilling, 2015, 43.

\subsection{Discussion of Competencies in African Countries}

Competency-based educational design is not unusual in African countries, and all these nations have changed track towards competency-based curricula within recent curriculum revisions. In this section, the common curriculum framework developed by the East African community is adopted as a representative case study in this piece of research, and specific discussions is held concerning the competencies described within the curricula. The East African Community has a common vision in school education for the purpose of smoothly conducting the transfer of education, economy, labor and services among the countries that are members of the community. Based on this vision within school education and the idea of social capital as something desirable, a common curriculum framework for East African communities was created, and a common curriculum framework for school education was proposed (East African Community, 2014). The framework indicates seven key competencies: 1) Communication 2) Mathematical Competencies 3) Personal and Social Competencies 4) Learning to Learn 5) ICT, Science and Technology Skills 6) Creative and Critical Thinking and 7) Cultural Considerations (East African Community, 2014). The detailed descriptions of learning outcomes for each competency are shown in Table 1.

The contents of the "Communication" and "Learning to Learn" competency categories defined by the East African Community, and the contents related to the three key competency categories advocated by the OECD "Definition and Selection of Competencies (DeSeCo)" Project were identical to each other. In short, non-cognitive ability to communicate appropriately and effectively in various social and cultural groups is a skill that is required in the East African community. Furthermore, it would be remarkable that "Creative and Critical Thinking" is set as one category in the competency defined by the East African community. It includes the words 'critical', 'courage', 'communication', 'creative' and 'perseverance', which cover all four dimensions previously proposed by the Curriculum Redesign Center. While these types of competencies would be important to live in the society regardless of developed or developing countries, it could also be more indispensable in the case of the developing countries as they are incredibly diverse and possess complex societal structures. The importance of statistical literacy has been increasing worldwide in recent years, and there is a tendency to emphasize the importance of statistical education at all stages of education. Similarly, the competencies exhibited within the East African community also include "Mathematical Competence" and "ICT and Scientific Technology", which is specifically indicated by the sentence "recognizes, understands, analyzes and responds to numerical and mathematical information such as statistics, graphs, tables and charts". Also, there are descriptions such as "Organization of information to support logic and inference" and "Recognize and appropriately use with confidence", which would indicate that in various situations, the focus that has been put on statistical results has been justly acknowledged as well as the ability to make decisions. In addition, the category of "Learning to Learn" is designated as one of the key competencies. This means that meta-learning listed as a characteristic of CCR is positioned as an important competency in the East African community. One of the learning outcomes is "Cultivating the desire and interest for lifelong learning and personal growth" and similar to the CCR, the 
importance of independent cognitive processes coming about from the goal of improving one's academic ability to facilitate lifelong learning is included.

Judging from the information provided above, it has become clear that the competencies exhibited in the East African community are very similar to those discussed in developed countries. In other words, against the background of rapidly increasing internationalization and globalization, the competencies required to live in the society of the future are the same across borders, regardless of whether in a developed country or a developing country.

Table 1. Competencies stipulated in common curriculum framework for East African communities

\begin{tabular}{|c|c|}
\hline es & \\
\hline Communication & $\begin{array}{l}\text { - Listen and respond to information on a variety of subjects. } \\
\text { - } \quad \text { Speak fluently and effectively to express his/her opinions. } \\
\text { - } \quad \text { Read and comprehend a variety of literary and non-literary text. } \\
\text { Express self effectively in written form. } \\
\text { different social and cultural contexts. } \\
\text { - } \quad \text { Use language for different audiences and purposes relevant to oneself and the subject. } \\
\text { - Understand and use the vocabulary, structures and forms of expression which characterize each area of study. }\end{array}$ \\
\hline $\begin{array}{l}\text { Mathematical } \\
\text { competence }\end{array}$ & $\begin{array}{l}\text { - Organize information to support logic reasoning. } \\
\text { - } \quad \text { Recognize and use numerical patterns and relationships confidently and competently. } \\
\text { - Recognize, understand, analyze and respond to information which is presented in numerical and } \\
\text { mathematical forms such as statistics, graphs, tables and charts as applied within the subject area. } \\
\text { - } \quad \text { Use a range of mathematical instruments, including electronics, confidently and competently. } \\
\text { - } \quad \text { Provide basic estimates and calculations accurately and proficiency. }\end{array}$ \\
\hline Learning to learn & $\begin{array}{l}\text { - } \quad \text { Take responsibility for his/her own learning. } \\
\text { - } \quad \text { Work effectively, independently and cooperatively. } \\
\text { - } \quad \text { Tevelop the desire and interest for life-long learning and personal growth. } \\
\text { - } \quad \text { Participate actively in meaningful learning activities. } \\
\text { - }\end{array}$ \\
\hline $\begin{array}{l}\text { ICT, scientific and } \\
\text { technological } \\
\text { competences }\end{array}$ & $\begin{array}{l}\text { - Develop awareness of scientific and technologic changes. } \\
\text { - } \quad \text { Appreciate the value and limitations of science and technology in the society. } \\
\text { individual and the society. } \\
\text { - } \quad \text { Participate appropriately in harnessing resources and energy for mutual benefit. } \\
\text { - } \quad \text { Make appropriate use of science and technology in solving problems at the individual and community level. } \\
\text { - } \quad \text { Use ICT devises competently. }\end{array}$ \\
\hline $\begin{array}{l}\text { Creative and } \\
\text { critical thinking. }\end{array}$ & 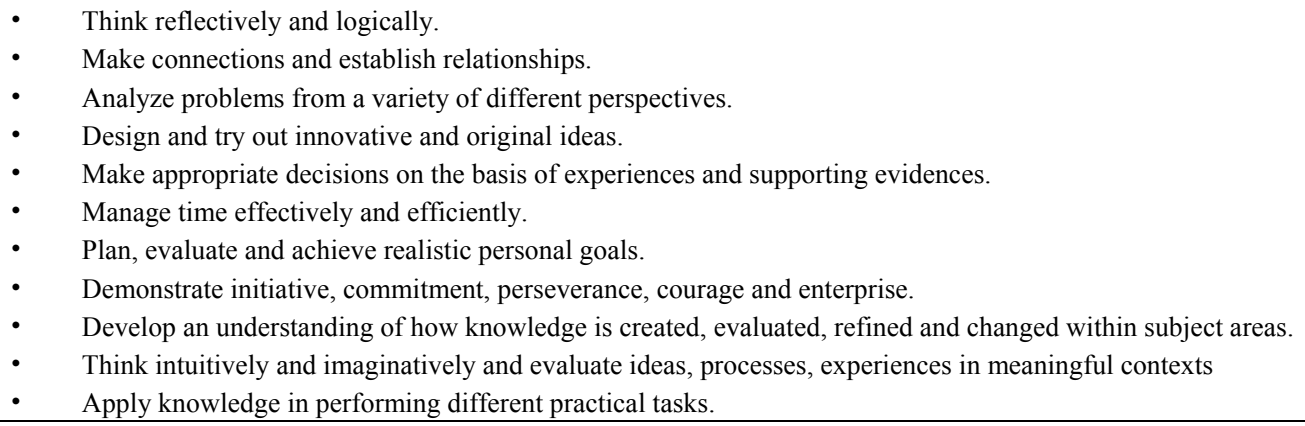 \\
\hline
\end{tabular}

Source. East African Community, 2014.

\subsection{How the Competence-Based Curriculum Design Affects Primary Math Education}

We will consider how these competencies are designed and aimed at, especially in mathematics education. As mentioned before, the concept of "key competencies" is used in the framework of the Programme for PISA, and can be seen within the fields of reading, mathematical and scientific literacies. The definition of mathematical literacy in the PISA 2018 assessment is as follows; "Mathematical literacy is an individual's capacity to formulate, employ and interpret mathematics in a variety of contexts. It includes reasoning mathematically and 
using mathematical concepts, procedures, facts and tools to describe, explain and predict phenomena. It assists individuals to recognise the role that mathematics plays in the world and to make the well-founded judgements and decisions needed by constructive, engaged and reflective citizens" (OECD, 2019, p. 75). This includes meanings such as capturing events in real life mathematically, judging various situations using mathematics, communicating with others using mathematics, and the significance and attitude of learning mathematics. In other words, it can be said that the characteristics of mathematical literacy in the PISA is to focus on the ability and attitude to use mathematical knowledge and skills in real life, which are beyond the scope of mathematics studied at school.

\subsection{Competency-Based Educational Design in Primary Mathematics Education in Mozambique}

Based on the discussin in previous sections, Mozambique is used as an example, analyzing the understanding and implementation of competencies in Mozambique's primary mathematics education from three aspects; curriculum, textbooks and classes, and clarifying its characteristics and the issues.

\subsubsection{Mozambique Primary Mathematics Education Curriculum Based on Competencies}

Mozambique's primary mathematics curriculum was revised in both 2004 and 2015. We highlight the characteristics of the competencies described in each curriculum by comparing the learning content related to natural numbers and calculations.

In addition to "themes", "purposes", and "contents", "competencies" are indicated to be the bedrock of educational content in both curricula. Regarding these, the 2004 curriculum contains a framework of "basic competencies", which lists mathematical skills such as "being able to read and write numbers up to 9" and "adding numbers up to 9". Similarly, this idea was also applied to other themes, and basic mathematical skills related to learning content, such as reading, writing, arithmetic, comparing, and arranging were also defined as competencies. However, in the 2015 curriculum, these were revised to be "partial competencies", where there was no statement of basic knowledge nor skills. Instead, practical competencies such as "solving problems related to daily life with numbers up to 10 " were listed. In other themes, "solving problems that are related to both everyday life and the learning content" and "applying the contents of learning to daily life" are listed as opposed to individual skills. This had been revised to define competencies as being applied to situations found in daily life and to solve various problems that occur around oneself, and not merely acquiring knowledge and skills. This can be comprehended as a change in the way of thinking about competencies between the years 2004 and 2015.

An emphasis was placed on the ability to use social, cultural and technological tools used in an interactive manner in the competencies that were defined in the 2015 mathematics curriculum, which was one of the key competencies proposed by the OECD "Definition and Selection of Competencies (DeSeCo)" project. Of course, the use of knowledge and skills in real life naturally calls for the ability to act autonomously and to collaborate with heterogeneous groups; hence, it would be assumed that all three categories contain both strengths and weaknesses. In the light of the four dimensions proposed by CCR, while there is a possibility that it is related to all the dimensions of knowledge, skills, human characteristics and meta-learning strategies, the contents of the curriculum are interpreted as having an emphasis on generic knowledge and skills that can be applied in real life.

Table 2. Description of competencies in 2004 curriculum

\begin{tabular}{llll}
\hline Unit theme & Specific objectives & Contents & Basic competency \\
\hline Natural numbers & Read and write numbers up to 9 & Numbers up to 6 to 9 & Read and write numbers up to 9, \\
and calculation & Add and subtract up to 9 & Reading and writing numbers 6 to 9. & Add and subtract up to 9. \\
& & Addition and subtraction up to 9 & \\
\hline
\end{tabular}

Source. Ministério da Educação, 2003.

Table 3. Description of competencies in 2015 curriculum

\begin{tabular}{llll}
\hline Unit theme & Specific objectives & Content & Partial competencies \\
\hline $\begin{array}{l}\text { Natural numbers } \\
\text { and calculation }\end{array}$ & Read and write numbers up to 10 & Reading and writing numbers up to 10. & $\begin{array}{l}\text { Solve the problems related to } \\
\text { daily life using numbers up to 10. }\end{array}$ \\
\hline
\end{tabular}

Source. Ministério da Educação, 2015. 


\subsubsection{Primary School Mathematics Textbooks}

In accordance with the revision of the curriculum, primary school mathematics textbooks have been revised annually starting from the first-year textbook by the National Institute for Educational Development (INDE) since 2016. In this section, how the mathematical competencies listed in the curriculum are grasped within the textbook and employed via an idiosyncratic approach (which in turn is related to issues such as the composition and presentation of content within first- and second-year textbooks) is considered from the point of view of how learning contents were displayed.

In the introduction of new learning contents, challenging scenarios and objects related to the real world are presented, followed by relevant questions. Problems related to real situations, such as math word problems, are introduced in new learning content with the aim of understanding sentences in some cases. In contrast; although the skill is used as a way of acquiring the ability to utilize them in subsequent practice exercises, the introduction of learning content focuses on mastering the algorithm and definition of calculation intermittently. More specifically, titles of some questions within the smaller units are 'Let's take a look! (Observa)' to present an example, and titles 'Let's try! (Completa)' 'Let's solve them! (Resolve)' and 'Let's fill them in! (Pinta)' lead children to solve questions; indicating simple definitions to children expecting children to apply the mathematical skills.

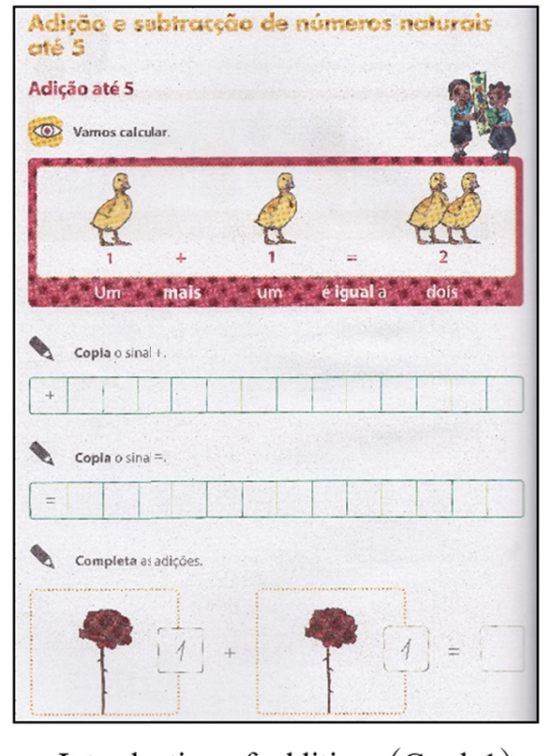

Introduction of addition（Grade1）

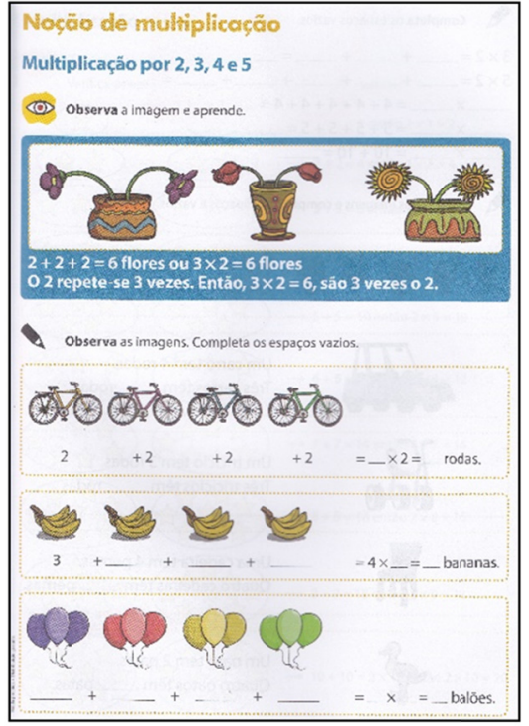

Introduction of multiplication (Grade2)

Figure 3. Examples of Grade $1 \& 2$ textbook

Source. Fumo, C., Guibungana, D., Nhabique, F., and Manhiça G., 2016, 2017.

In the introduction of the unit meter in the area of "quantity and measurement" for first-year students, personally observable examples are presented while children engaged in measurement activities. Thus, the contents described in the competencies are specified within the textbooks. On the other hand, when measuring concrete objects presented in textbooks, there will always be a fraction that could not be measured in $\mathrm{m}$ (such as $\mathrm{cm}$ ), and this should be led into the introduction of $\mathrm{cm}$. However, the relationship between $\mathrm{m}$ and $\mathrm{cm}$ is covered in the second grade. In other words, although problem-solving activities related to daily life are presented and learning is promoted on the basis of activities undertaken, they ignore the continuity of previous and subsequent learning. Unless the teacher fully understands the contents and provide sufficient instructions, including the areas that contradict each other, it may interfere with children understanding the content in a comfortable manner.

The primary mathematics curriculum includes practical competencies related to daily life such as the ability to "solve problems related to daily life regarding of learning contents" and the ability to "apply learning contents to daily life". The introduction of new mathematical concepts in the textbook use concrete materials and hands-on teaching materials and tools. One could also get a sense of this in the math word problems that are presented after moving beyond abstract computation and confirmation problems. However, most of the "number and 
arithmetic" areas particularly emphasize the "basic competencies", and the extent to which practical competencies described in the curriculum are nurtured are largely reliant on the abilities of the teacher applying the lessons in the classroom.

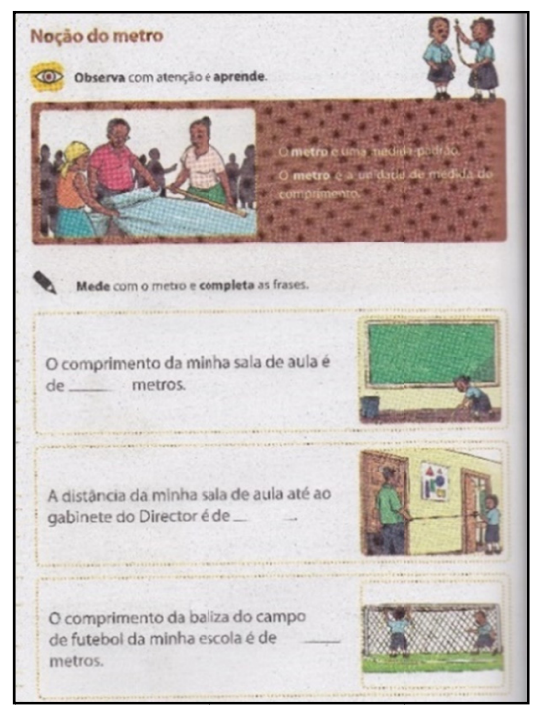

Figure 4. Introduction of metre (Grade1)

Souce. Fumo, C., Guibungana, D., Nhabique, F., and Manhiça G., 2016.

\subsubsection{Acquisition of Practical Competencies in Primary School Mathematics Classes}

Two mathematics classes at a public primary school in Mozambique and their basic outlines are described in this section. Next, issues concerning the features common to each class based on the viewpoint of the competencies described in the curriculum are considered.

Lesson 1: Grade 4 angle classification lesson at a public primary school in Maputo

- The teacher taught the types of angles via oral instruction or by writing on the board. While some children jotted down the board notes, others did not.

- Following this lesson, how to present angles was explained, and examples of right angles, acute angles, and obtuse angles were taught. On this occasion, the teacher asked students what angle was. However, an explanation that implied where the angle was located was given without waiting for students to answer. Furthermore, confirmation of understanding concerning the nature of the angle was not performed. While those children were able to understand the location of the angle, they may not have been able to understand the size of the opening was the angle.

- When explaining the types of angles and how to represent them, teachers used many alphabetical characters to emphasize the notation of " $\angle \mathrm{ABC}$ ". In Japanese setting, this is an abstract notation that would usually be handled from junior high school onwards. Additionally, this learning content is not something that closely follows the children's understanding of everyday things. Therefore, it was questionable as to the extent the children could understand the concept of angles.

- Following the explanation of the types of angles and how they should be represented, the teacher asked the students to write right, acute and obtuse angles on the blackboard. The correct answers were provided in a timely manner while confirmation of understanding was attained from all the children, but since students other than the one who answered did not copy the answer on the notebooks, confirmation of the knowledge may have limited within the individual.

Lesson 2: Grade 4 Roman numeral calculation class at a public primary school in Maputo

- The lesson involved calculation using Roman numerals up to 100 and solving practice exercises in the textbook. The teacher first asked the students to solve a comprehension problem. They then went over the answer, and then instructed the students to complete the practice exercises.

- Calculations were performed with Roman numerals and were then converted to Arabic numerals. However, it 
seemed the teachers were not of the conceptual view that they should be forming numbers borne from the characteristics of Roman numerals using the numbers 5 and 10 as a base.

- Some students made mistakes when converting the numbers. There was also a problem that the answer to the comprehension question was checked by the teacher in concert with the students, but that the answer(s) provided was incorrect.

- The students who provided their answers by being called up to the blackboard during this class were always the same children. There were no opportunities to discuss mistakes, nor for other children to present their work.

\subsubsection{Features and Challenges Common to Each Class from a Competency-Based Perspective}

Both classes were conducted by teachers through blackboard writing. Both class structures were lecture style, which teachers directly explain important mathematical concepts while verbally going over the contents with the children. It seemed that there were many classes that presented the problems in textbooks on a verbatim basis. The activities provided in actual math classes were mostly related to "basic competencies" that were directly linked to basic knowledge and skills. The point has been raised that, for example, there was no individual nor group learning conducted in class to nurture the ability to work autonomously or cooperate with heterogeneous groups, which themselves are elements of the key competencies proposed by the OECD. The observed class had a process that teachers presented new definitions and knowledge; while students repeated and revised them, and then familiarize themselves with the content via practice questions. The students do not have opportunities to think and discuss the contents amongst themselves; thus, there is no space where ideas or proposals could be further spawned. This might prevent the establishment of knowledge and skills. To this end, it may be necessary for one to work on human characteristics such as the curiosity of children in order to foster practical competencies from the viewpoint of the education dimension advocated by CCR. Likewise, children can also demonstrate their own leadership to solve these problems. There may be a need for classes that foster the resilience that require to think, overcome concerns regarding the contents and discuss contents until they are able to reach a singular conclusion or revelation. It could be said that it is essential to first develop the understanding of teachers' practical competencies and the ability to conduct classes while appropriately executing them in order to nurture the practical competencies of children described in these curriculm.

To sum up, Although the curriculum is in line with the global trend in terms of competency-based education, it became clear that there was a big gap between the curriculum and textbooks. Moreover, teachers who are teaching along with the current textbooks were difficult to provide the lessons to improve students's competencies written in the curriculum. Revison of the textbooks have been procceding currently, therefore it is expected that textbooks in line with the new curriculum are developed. The future challenge is also to improve the capacity of teachers to conduct lessons that foster students' competencies.

\section{Conclusion}

This paper examined the similarities and differences between competencies discussed mainly in developed countries and competencies discussed in African countries from the perspective of competency based educational design in African nations, and clarify the characteristics of each approach. Next, using Mozambique as an example, we tried to clarify how this country's primary mathematics education curriculum, textbooks, classes, etc. were developed and what issues were being confronted.

There was no significant change in learning content comparing the curriculum between 2004 and 2015, but it became clear that competencies were revised from content related to basic knowledge and skills to content related to practical skills. An emphasis was placed on the ability to use social, cultural and technological tools used in an interactive manner in the competencies that were contained in the 2015 curriculum. Indeed, this was one of the key competencies proposed by the OECD "Definition and Selection of Competencies (DeSeCo)" project. However, most of the contents of the new textbook focus on "basic competencies" centered on basic knowledge and skills. Furthermore, there were many classes where teachers presented questions listed in the textbook as they are. Hence, it became apparent that the nurturing of practical competencies listed in the curriculum was largely reliant on the abilities of the teacher. In other words, there was a big gap in the contents of the "textbook" that should serve as a bridge between the intended and practiced curriculum. Furthermore, another issue could be the teachers' insufficient understanding of the content of the practical competencies described in the curriculum and abilities to carry out the class.

While Mozambique is no more than a case study, the accumulation of such basic research has implications for improving the quality of education. It is hoped that similar studies can be performed in other African nations. 


\section{References}

Bernard, J., Nkengne, A., \& Robert, F. (2007). La relation entre réformes des programmes scolaires et acquisitions à l'école primaire en Afrique : réalité ou fantasme? L'exemple de l'approche par les compétences, Dijon, Institut de Recherche sur l'Éducation, Université de Bourgogne. https://doi.org/10.1007/s11159-007-9054-z

Collins, A., \& Halverson, R. (2009). Rethinking Education in the Age of Technology: The Digital Revolution and the Schools. New York: Teachers College Press.

Duave, A., \& Chirindza, F. (2008). Vamos aprender a contar Matemática $1{ }^{a}$ Classe (Libro Caderno). Maputo, Moçambique: Macmillan Moçambique Lda.

East African Community. (2014). Draft harmonized curriculum structures and framework for the east African community primary education. Arusha: East African Community.

European Commission. (2007). Key competences for lifelong learning: European reference framework. Luxembourg: Office for Official Publications of the European Communities.

Fadel, C., Bialik, M., \& Trilling, B. (2015). Four-Dimensional Education: The Competencies Learners Need to Succeed. La Vergne, TN, USA: Lightning Source Inc.

Fumo, C., Guibungana, D., Nhabique, F., \& Manhiça, G. (2016). O mundo da matemática, Livro de Aluno (Livro Caderno). Matemática $1^{\mathrm{a}}$ classe. Maputo, Moçambique: Ministerio da Educação.

Griffin, P., McGaw, B., \& Care, E. (Eds.). (2012). Assessment and teaching of 21st Century Skills: Methods and approach. Netherlands: Springer. https://doi.org/10.1007/978-94-007-2324-5

Howells, K. (2018). The future of education and skills: education 2030: The future we want. Working Paper. Paris: OECD.

Ministério da Educação. (2003). Programa de MATEMÁTICA para o $1^{\circ}$ Ciclo do Ensino Básico. Mozambique, Ministério da Educação.

Ministério da Educação. (2015). Programas do Ensino Primário Língua Portuguesa, Matemática e Educação Física. Mozambique, Ministério da Educação.

OECD. (2003). The Definition and Selection of Key Competencies Executive Summary. Paris: OECD. Retrieved November 3, 2019, from http://www.oecd.org/pisa/35070367.pdf

OECD. (2019). PISA 2018 Assessment and Analytical Framework. PISA, OECD Publishing, Paris.

Roegier, X. (2008) L'approche par compétences en Afrique francophone, IBE Working Papers on Curricular Issues. Genève, IBE/Unesco.

Rychen, D. S., \& Salganic, L. H. (Eds.) (2003). Key Competencies: For a Successful Life and a Well-Functioning Society. Cambridge, MA, USA: Hogrefe \& Huber.

UNESCO-IBE. (2013). Training Tools for Curriculum Development: A Resource Pack. Geneva, Switzerland, IBE-UNESCO.

UNESCO-IBE. (2015). What Makes a Good Quality Curriculum? In-Progress Reflections No 2. Geneva, Switzerland, IBE-UNESCO.

\section{Copyrights}

Copyright for this article is retained by the author, with first publication rights granted to the journal.

This is an open-access article distributed under the terms and conditions of the Creative Commons Attribution license (http://creativecommons.org/licenses/by/4.0/). 